\title{
DIAMOND-LIKE CARBON FILMS AS WEAR-PROTECTIVE COATINGS on MEDIA and HEAD SIIDERS
}

\begin{abstract}
John Sivertsen, Geng Wang+, Ga-Lane Chen* and Jack Judy** The Center for Micromagnetics and Information Technology, Dept. of Mat. S.,**Dept. of E.E., U. of Minn., Minneapolis, MN 55455, +Samsung Inc., Milpitas, CA,*Seagate Tech., Recording Division, Milpitas, CA 95035
\end{abstract}

ABSTRACT: To achieve ultra-high recording density, flying heights of less than one micro-inch are required which lead to a tribology of the HDI (head-disk interface) limiting disk drive design. Various amorphous diamond-like or DLC type carbon films have been developed for wear protection. At first pure carbon(C) sputtered films were used, followed by $\mathrm{C}: \mathrm{H}$ (hydrogenated carbon) and $\mathrm{C}: \mathrm{N}(\mathrm{ni}-$ trided carbon) films with generally superior wear performance. Because of the near- or quasicontact nature of the wear process, we have used mainly (CDT) CONTINUOUS DRAG TESTING for our evaluations, along with identifying bond character, nanohardness, microscopies of surfaces and bulk of films etc., to establish the nature of initial wear damage and dependence on as-deposited film structure(atomic \& electronicl. The purpose: Control deposition processes-to control the structure-thus control properties.

\section{INTRODUCTION}

Briefly we consider wear performance of pure $C$ and $C: N$ films in direct contact at HDI, consistent with quasi-contact at HDI. Total structure (atomic and electronic) is desired to establish the nature of initiation of the wear. Results on $\mathrm{C}: \mathrm{H}$ will also be given to supplement results for pure $C$ and $C: N$ films. Differences in process and composition will control bond character, the crystal structure (or lack of it), surface roughness etc. at the HDI and is considered.

\section{CHARACTER OF DLC FILMS}

i) Atomic Array in DLC Films. As a rule, DLC films consist of mixed crystalline and amorphous (may be nanocrystallinel C phases. Relative phase mix depends on conditions of sputtering (partial pres -sures of sputter gases, termerature of substrate etc. and the sputter method used(DC Magnetron, RF Diode, Facing Target Sputtering (FTS) etc. $L$ Crystal phases in films are sparsely distributed in amorphous matrix yielding a diffraction pattern of weak rings superposed on a strong centrally located Dackground as in TEM or transmission electron microscope diffraction.

ii) Electronic Bond Character in DLC Films. Elemental composition and bond character of DLC films are determined by $X$-ray photoelectron spectros copy (XPS), Auger Electron Spectroscopy (AES), and recently Electron Energy Loss as Spectros copy (EELS) [I] . Results obtained may be used to evaluate composition profiles, nature of bonding such as relative $\mathrm{sp} / / \mathrm{sp}^{2}$ bond ratio, density of film, etc. EELS data [2] for graphite, films of $C$ and $C: N$ deposited by FTS are shown in Fig. I indicating a $c: N$ film exhibits a much smaller sp ${ }^{2}$ bond peak at $285 \mathrm{eV}$ and thus much greater $s \mathrm{p}^{3} / \mathrm{sp}^{2}$ bond ratio than $a$ pure $C$ film.

Estimates of relative $\mathrm{sp} 3 / \mathrm{sp}^{2}$ bond ratios by AES and XPS show a good agreement with EELS [2]. (Note --EELS provides simultaneous bond characterizationsthigh resolution micrography by TEM.I Fig. 2 hence 


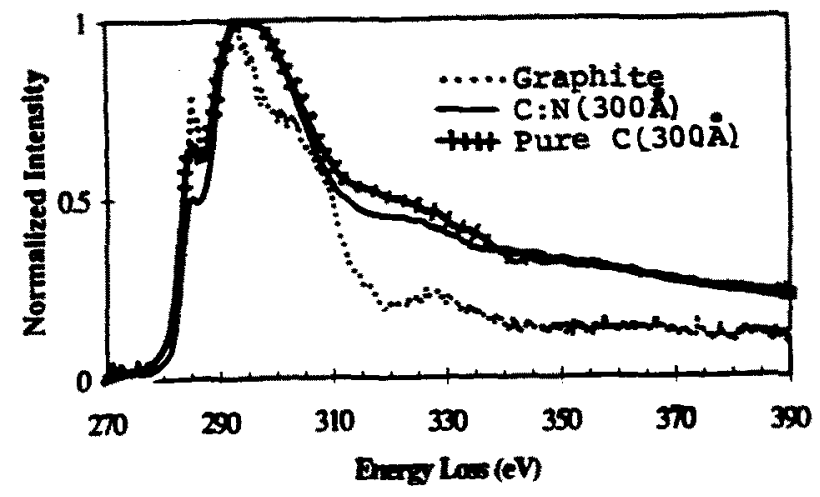

Fig. 1. The EELS carbon(K-edgel spectra of graphite and films of pure $\mathrm{C}$ and $\mathrm{C}: \mathrm{N}$ sputtered by FTS [2].

shows a TEM micrograph of DC.Magnetron sputtered pure $C$ film;note graphite nano-particles. FTS $C: N$ films exhibit much greater microstructural uniformity compared to the pure C film(Fig. 2) as is expected for a material with higher $\mathrm{sp}^{3} / \mathrm{sp}^{2}$ bond ratio(Fig.1) and is a general result [3].

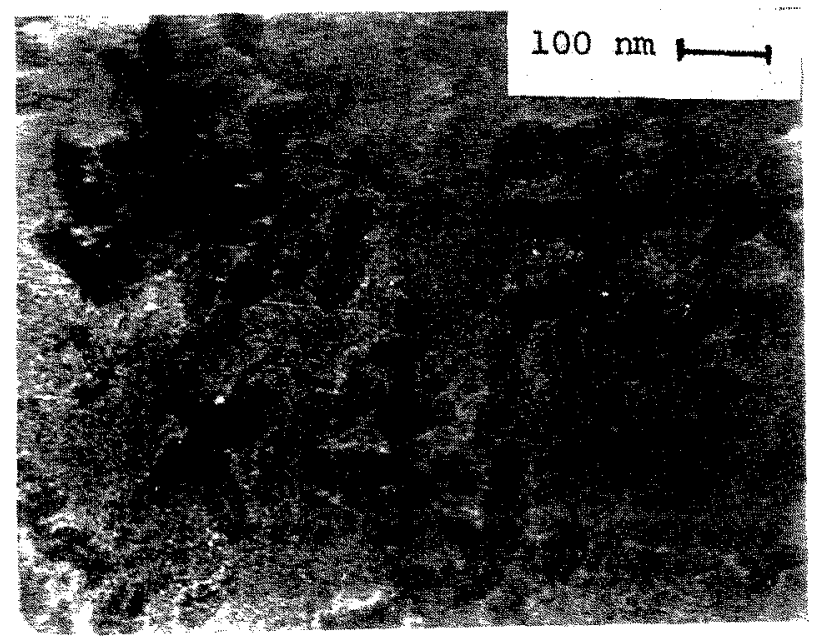

Fig. 2. TEM micrograph $\left(10^{5} \mathrm{X}\right)$ of pure DLC carbon (DC Magnetron) on a commercial disk; note nano -particles of graphite (C. Leu).

iii) Surface Roughness Features. Surface roughness and conformation of mating surfaces of the HDI have important effects on wear performance of DLC films.
A critical factor is the 'surface roughness' or smoothness. Fig. 3 shows AFM images of the air-bearing surface of a 708 head slider, (a) uncoated and (b) subsequently coated with $5.0 \mathrm{~nm}$ of pure C/FTs. As can be seen, the DLC coating considerably reduces 'roughness' of head slider surface. A recent report [4] on continuous drag(CDT) tests of uncoated, c-coated and $C: N$-coated head sliders on commercial DLC coated disks showed that after $23 \mathrm{~K}$ cycles of $C D T, C: N$ coated sliders suffered least of damage of the three types with a significantly smoother off-track surface as well.

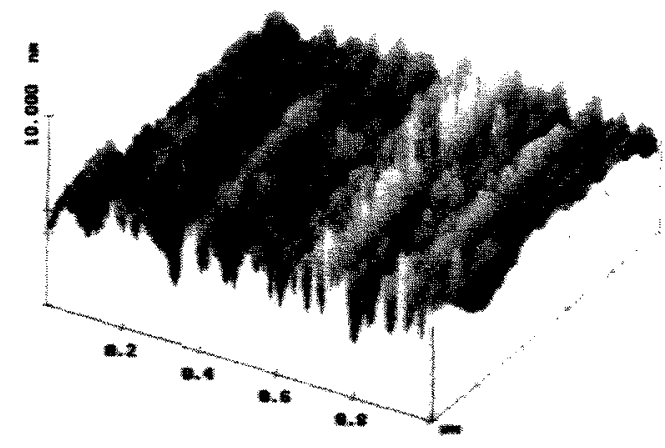

(a)

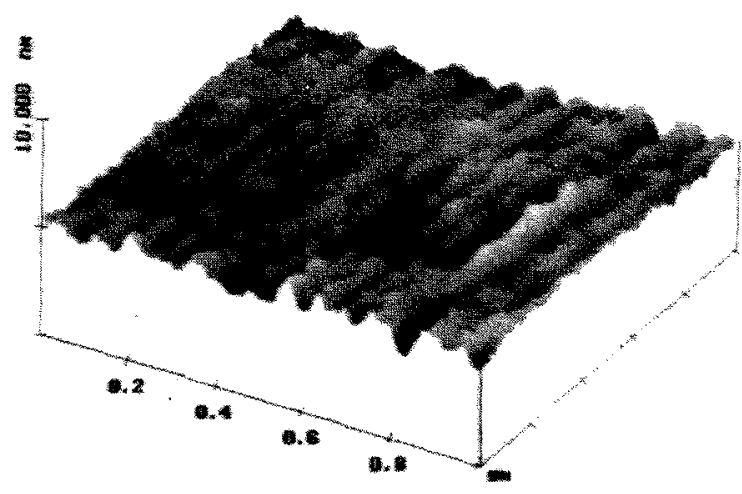

(b)

Fig. 3. AFM images of atr bearling surfaces of (a) uncoated and (b) subsequently coated $(5 \mathrm{~nm})$ with a pure C(FTS) film [4]. 
Measurements were performed of initial take-off velocities of a number of head sliders from disks coated with varying contents of the DLC coating. Films were deposited on standard 'commercial' disk substrates at various partial pressures $P\left(\mathrm{~N}_{2}\right)$ of $\mathrm{N}_{2}$ in an Ar gas mixture of total pressure lomtorr. All tests were done at a radius of $0.9 "$ with $70 \%$ sliders. The results [5] shown in Fig. 4 indicate a definite monotonic decrease in take-off velocity with $\mathrm{N}_{2}$ gas partial pressure implying an increasingly smoother surface with increasing $C: N$ film content.

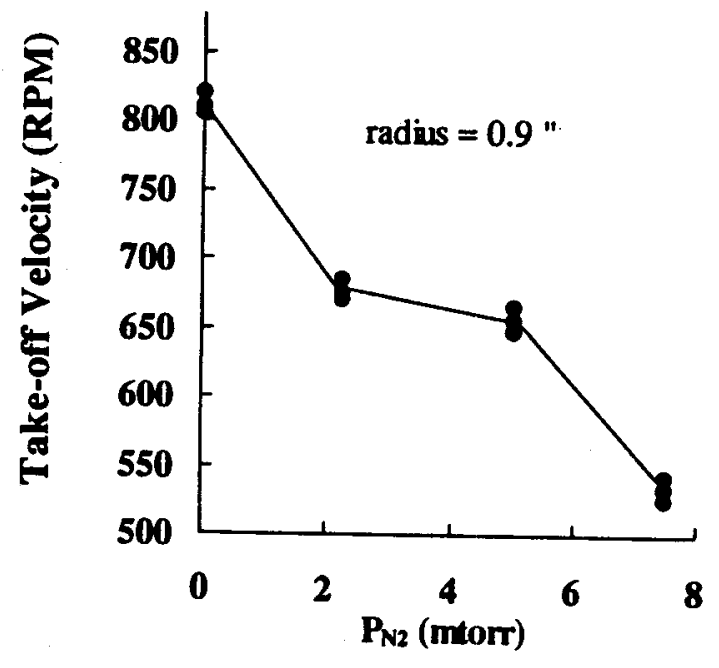

Fig. 4. Initial take-off velocity (RPM) at $r=0.9$ " vs $P\left(\mathrm{~N}_{2}\right)$ (mtorr) of $\mathrm{N}_{2}$ in Ar mixture of total gas pressure $=10 \mathrm{mtorr}[5]$.

iv) Optical Properties. Optical property measurements allow evaluations of the optical band gap, $\mathrm{E}_{\mathrm{g}}$, which also confirmed that sp3 type bonding in C:N films is greater than in pure $C$ films $[6,7]$.

NANO-INDENTATION PROPERTIES.

Important considerations in DLC film wear performance are hardness and elastic compliance. To compare these characteristics for DLC of C and $C: N$ type coatings, continuous nano-indentation tests were performed with a Triboscope TM. The Triboscope is load-controlled of sensitivity 1.8 nanoNewtons and a depth resolution of $0.2 \mathrm{~nm}$. When attached to a conventional AFM it enables one to scan a surface before indentation and to image the resulting indent immediately after an indentation. The indenter tip used was a standard scanning tunneling microscope (STM) pyramidal boron-doped diamond tip with a radius of $100 \mathrm{~nm}$ (included $72^{\circ}$ anglel.

Measurements of hardness and modulus were performed on $C$ and $C: N$ films ranging in thickness on head sliders. Data[2] for $100 \mathrm{~nm}$ thick $C$ and $C: N$ coatings obtained with Triboscope TM are shown in Fig. 5. The hardness and modulus were derermined from these data by the method of Doerner and Nix [8] shown in Fig. 6.

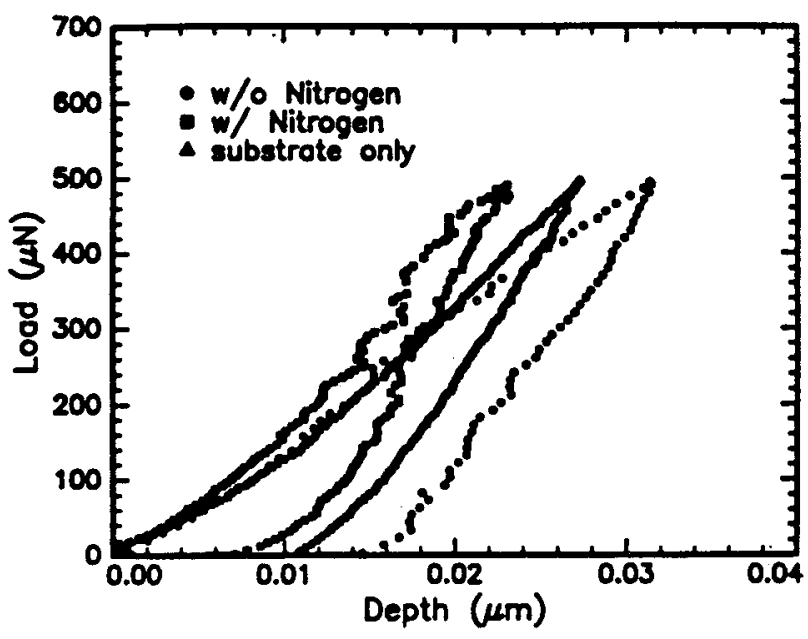

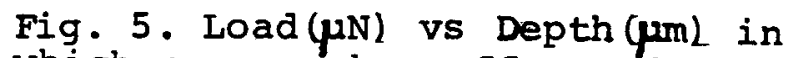
which curves show effect of $P\left(\mathrm{~N}_{2}\right)$ and hence $\mathrm{N}_{2}$ on the modulus of $\mathrm{a}$ DLC film. The $C: N$ film is harder than a plain C film without nitrogen. Waviness of curves is due to cracking of the films[2]. 


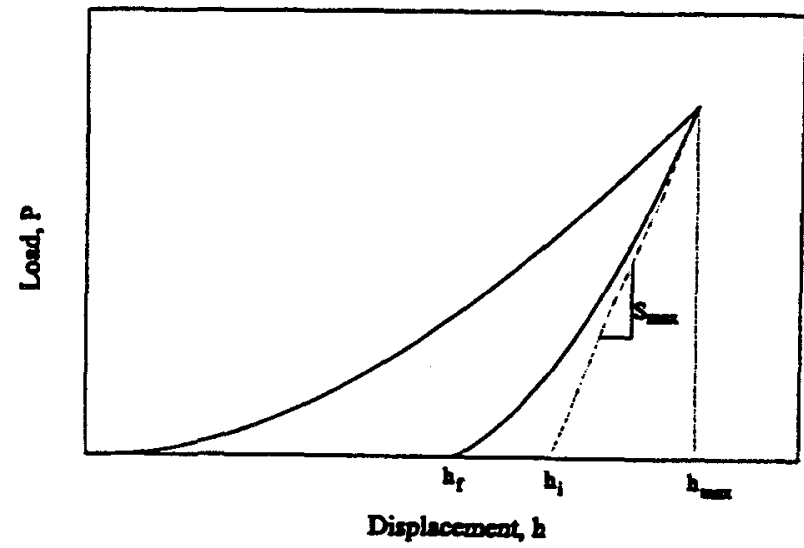

Fig. 6. Schematic of the method of Doerner and Nix[8].

Using the upper one-third of an unloading curve slope, a reduced MODULUS $E *$ and the HARDNESS $\mathrm{H}$ are given by

$$
\text { and } \mathrm{H}=\mathrm{P}_{\max } / \mathrm{A}
$$

$$
E^{*}=(\sqrt{T T / 4}) \frac{(\mathrm{dP} / d \mathrm{~h})}{\sqrt{ } \mathrm{A}}
$$

$$
\begin{aligned}
& \text { where } \mathrm{A}=\text { area of indent } \\
& =\mathrm{II}\left(2 \mathrm{R}-\mathrm{h}_{\mathrm{C}}\right)^{2}, \\
& \begin{aligned}
\mathrm{h}_{\mathrm{C}}=\mathrm{contact} \text { depth } \\
=\mathrm{h}_{\max }-\mathrm{EP}_{\max } /(\mathrm{dP} / \mathrm{dh}) \\
\mathrm{dP} / \mathrm{dh}=\text { Iinear } \mathrm{fit} \text { slope } \\
\text { of upper } 1 / 3 \text { of } \\
\text { unload curve } \\
\mathrm{R}=\text { radius of indenter } \\
\mathrm{h}_{\max }=\text { maximum penetration } \\
\mathrm{P}_{\max }=\text { maxth }
\end{aligned}
\end{aligned}
$$

and $\mathbf{S}$ is a parameter that depends on the indenter tip shape.

The results of [2] give $427 \mathrm{GPa}$ for the $C: N$ modulus which is much greater than the pure $C$ modulus, which is $272 \mathrm{GPa}$; the modulus of the head slider material $=330 \mathrm{GPa}$. The hardness for these three materials is $23.5 \mathrm{GPa}$ for $\mathrm{C}: \mathrm{N}, 21.5$ GPa for pure $C$, and $18.5 \mathrm{GPa}$ for the $\mathrm{Al}_{2} \mathrm{O}_{3}-\mathrm{TiO}_{3}$ head slider.

\section{TRIBOLOGY OF DLC FILMS}

The obvious properties that are required of wear-protective films are to: il be as thin as possible, ii) have no asperities for mechanical contact, iiil resist coating wear and inflict no slider "wear", iv) have minimum friction, v)protect media from corrosion, exhibiting good tribochemical behavior, vi) bond to media, not to slider, and vii) have high hardness (yield strength) and fracture toughness.

In regard to (i), reproducible, pinhole-free $9.0 \mathrm{~nm}$ thick DLC films of pure $C$ and $C: N$ can be deposited without need of adhesion underlayers. Thinner films (7.5-5.0nm) low in yield have been deposited, but may be improved using an adhesion underlayer and high deposition energy.

In regard to (ii), Yeh et al[s] showed that the initial 'take-off velocity' decreases with increase. in nitrogen gas pressure $\mathrm{P}\left(\mathrm{N}_{2}\right)$; as in Fig. 4. This implies a smoother surface for $C: N$ films on disks com -pared to that of pure $C$ films con -sistent with results shown in the Fig. 3 for slider surfaces.

With respect to (iii), Yeh [3] and Wang et al[9] have shown that $C$ and $C: N$ films may be sputtered with kinetic friction coefficient in the range $0.12-0.20$ and by care in processing develop coefficient values of $0.08-0.1$ for $C: N$ films. In case (iv), Torng[10] has shown that $C: N$ films have superior corrosion resistance by no reactions in various acid solutions: $\mathrm{ACl}$, $\mathrm{HNO}_{3}-\mathrm{HCl}-\mathrm{CH}_{3} \mathrm{COOH}$, $\mathrm{HCl}-\mathrm{HNO}_{3}$, and HF. For (v), C:N films exhibit no delaminations as-deposited, while pure C films tend to 'wrinkle' on deposition due to a compressive stress state developed during the deposition [10].

As regards (vi), wang et al[4,9] have used CDT to study wear on sliders to show wear resistance in direct contact under various conditions or combinations that form the HDI, given as follows: Wear performance studies were made by CDT (direct contact testI 
of uncoated and coated $70 \%$ headsliders on various lubricated and unlubricated standard commercial

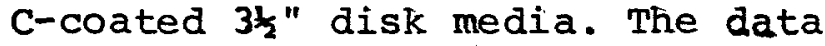
results in Fig. 7 \& 8 show: wearresistance of $\mathrm{C}: \mathrm{N}$-coatings are in fact superior to those of $\mathrm{C}-$ and $\mathrm{C}: \mathrm{H}$-coatings. Wang et al[4]reported on the wear resistance of uncoated and of $\mathrm{C}-$ and $\mathrm{C}: \mathrm{N}$-coated (9.0 nm) sliders on unlubricated, commercial $\mathrm{C}: \mathrm{H}$-coated media. The results [4] in Fig. 8 showed that uncoated sliders had the highest kinetic friction and $\mathrm{C}: \mathrm{N}$-coated sliders had the lowest after $20 \mathrm{~K}$ cycles.

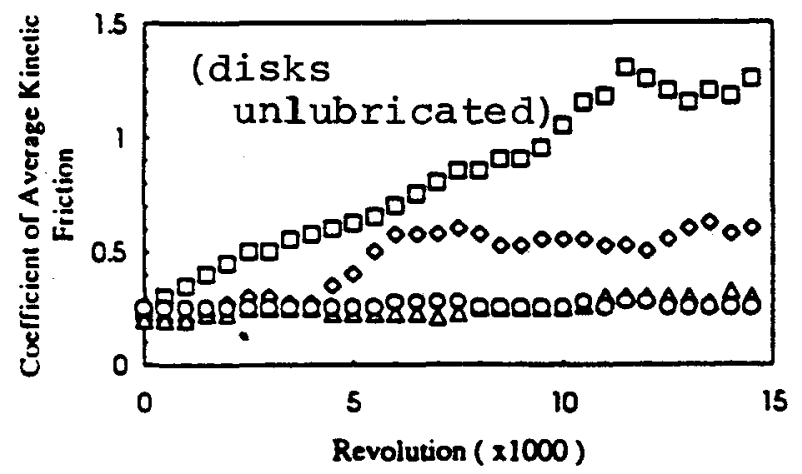

(a)

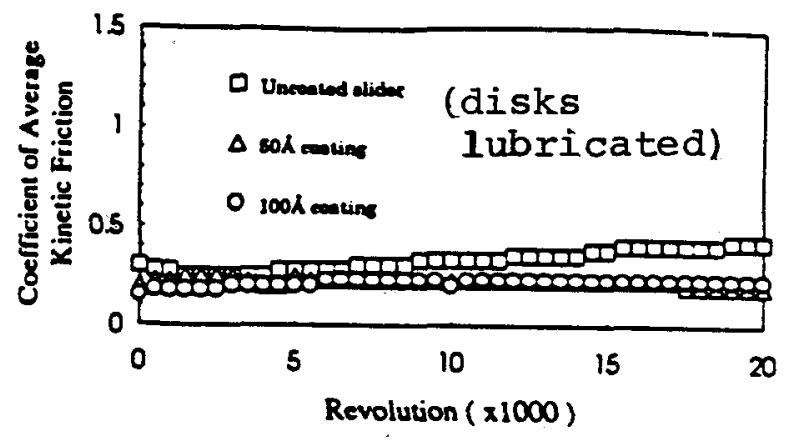

(b)

Fig. $7(a)$. Coefficient of kinetic friction vs revolutions with and without C-coated sliders. Ccoated disks without lubricant. $\square$ uncoated slider; $\theta$ slider $c-$ coated $(15.0 \mathrm{~nm}), \Delta$ slider coated (30.0nm C) by DC magnetron; $O$ slider with $15.0 \mathrm{~nm}$ C by FTS... (b) kinetic friction vs number revolutions with and without $\mathrm{C}$ coated sliders; C-coated disks [9]

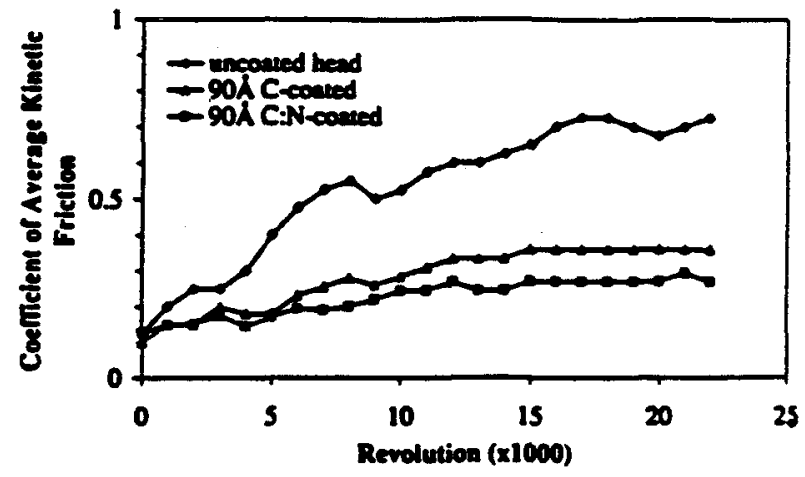

Fig. 8. The coefficient of kinetic friction vs revolutions for heads coated with and without pure $C$, and $C: N$ coating on heads deposited by FTS. Disk media were C:H-coated without Iubricant 642 .

In all cases, best wear test performance was by $C: N$-coated headsliders with uncoated sliders having poorest. Note: pure c-coated sliders performed about as well as $C: N$-coated sliders when deposited by FTS. Fresh heads were used for each $C D T$ run, performed at a maximum energy dissipation rate. Also, zou et al[II] reported quasi-contact test results showing $C: N$ coatings performed better the higher the nitrogen content. Similar type results are reported by Lal et al[il]

The physical character of initial wear damage features in the DLC films is significant. E.g., in $\mathrm{C}: \mathrm{H}$ films initial damage appears as a random distribution of fine hard particles of sub-micron size along the wear track; Cf. Fig. 9 [4]. For C:N films [3], the initial wear damage is similar to an adiabatic shear banding due to plastic flow about the wear track with gradual thinning along the track; Fig. 10. Note: apparent wear marks in Fig. $10(b)$ are an effect of disk texture, while (a) exhibits an early stage flow damage. Comparably the initial damage in pure $C$ DC magnetron sputtered films appeared as ductile tearing of sub-micron to micron size, randomly distributed around the wear track, added wear 
occurring by enlargement of worn sites during repeated wear cycles.

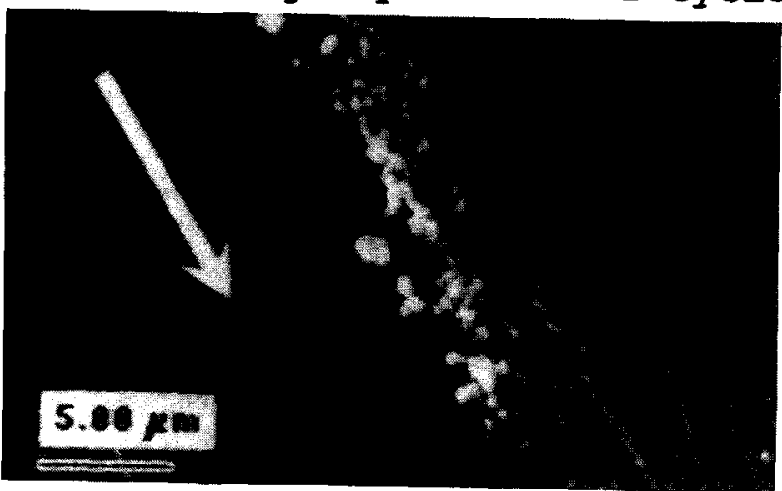

Fig, 2. SEM micrograph of a wear track on a C:H-coated disk using an uncoated slider after CDT.

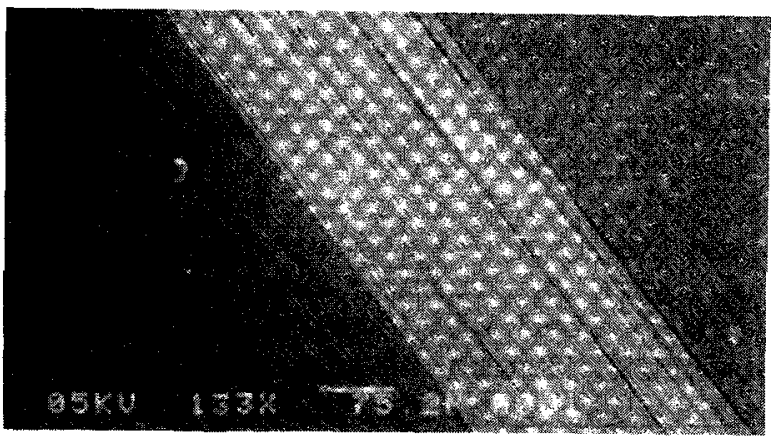

(a)

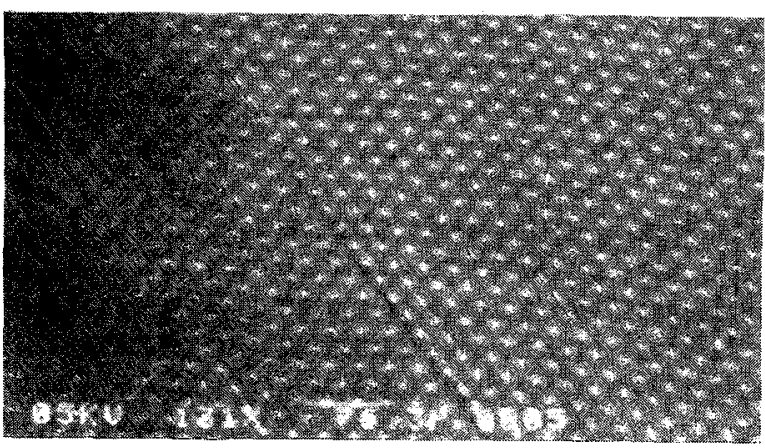

(b)

Fig. 10. SEM micrographs of a wear track on al $C: N$ coating with a low sp $3 / \mathrm{sp}^{2}$ after $5 \mathrm{~K}$ cycles, $\mathrm{bL} \mathrm{C}: \mathrm{N}$ with high $s p^{3} / s^{2}$ after $9 R$ cycles using uncoated sliders.

\section{CONCLUSIONS}

We conclude that amorphous $C: N$ is a superior wear-protective coating for thin film media and head sliders because $C: N-1$ ) has high hardness, high modulus plus frac- ture toughness correlating with a high $\mathrm{sp}^{3} / \mathrm{sp}^{2}$ bond ratio, 2 2 shows exceptional corrosion resistance, 3) has good surface smoothness + a coefficient of friction attainable in the 0.15-0.20 range, 4) has a homogeneous composition and a uniform structure which reduce a tendency to form local stress concentrations that may initiate submicron catastrophic wear damage, 51 a minimal environmental probler when compared to $C: H$ formed by chemical vapor deposition, and 61 can be up -graded by increasing physical den -sity and sp 3 bonding by optimizing deposition processes; e.g., a RF, or FTS etc. sputtering method.

\section{REFERENCES}

1. c. Weisomantel, X. Bewilogua, c. Schurer, $\pi$. Braur and $\mathrm{B}$. 2acheile. "Conracterising Bard Carbon Filis by Electron Enaryy iose Spectroncopy". Min Solid Film, 61.il, (1979)

2. G. Wang, A. strojny, J.H. Sivertsen, J.B. ties of pure Carbon and Carbon-Nitrogen co tings on thin Fill Baed SIIders", Proc. Mat. Rosearch Soc. (XTS) Conf. (San Francisco, CA). $4 / 96$

3. T.A. Yeh, "Daposition, Characterization and Tribological Studies on carbon overcoats for Magnetic Storage Devices",Ph.D. Thesis, o. of planesota, $9 / 23$.

4. G. Nang, J.A. SIverteen, J. Judy and G.L. Chen, "Comparison of Tribological Perfora ance of Pure carbon and Carbon-kitrogen Coated thin Fila Head slidera",J. Applied hye , 79,5782, (1996)

5. T.A. Yeh, C.L. Lin, J.M. Sivertsen and J.A. Judy, "Durability and Structure of RF Sputtered Carbon-Ritrogen Thin Filn overcoats on RIgtd Disks of kagnetic Thin Filn Nidia IEEE Trans. On wag.., Me-27,5163, (2991)

6. C.J. Torng, "Deposition and Characterizations of $C: N$ Thin Filne tor both Electronic and Magnatic Device Applieation ",Ph.D. Thesis c. of Minesota, $10 / 91$.

7. C.J. romg, T.A. Yeh, J.K. Siverteen, s.s. Lu, and $A$. Copinath, "Deposition and charac terization of C:A Film on 51 for Mcxoelectronic Application",Proc. 2nd Int'l Conf. on New Diawiond Science

8. M.F. Doerner and W.D. Bix, "A Nethod for Interpreting the Data from Depth-Senting Indentation Instrument", J. Mat. Res.,1,601. dentation

9. G. Wang, T.A. Yeh, J.X. Siverteen and J. Judy, "Tribological and pecording Performance of carbon-Nitrogen inin film Bead silders on Unlubricated and Lubricated Thin Filn vedia". IEEE Irans, on Mag. .MAG-30,4125. CI994L.

10. C.J. Torng; J.K. Sivertsen, J.B. Judy and C.T. Chang. - Structure and Bonding Studies of $C: N$ Pilms Produced by $R F$ Sputtering*,J. Mat. Bas. 5. 2490, (1990L.

11. $\bar{P}$. Zou, M. Scherge and D.N. Lambeth, "OvasiConeact Testing of C:N Bard Disk OvercoatsIEEs Trans. on mag.,.MgG-31,2985, (1995):B. IÁl,

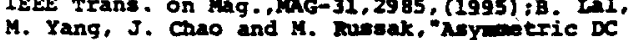

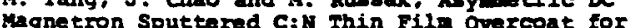
Rigid Disk Applieations-, I wese Trans. on Mag." MAG-32, (2996).

12. T. Yeh, C. Leu, C.T. Chang, J.M. Siverteen, and $J$. Judy, "Initiation of sliding Wear of the HDI at Very Low potational velocity", IEEE Trans on Mag., me-24, 2650, (1988), Yeh. C.T. Chang, J.K. Sivertsen and J. Judy. -Sliding Damage and Strose stite of iultilayer Thin Film Rigid Disk dia,J. Mag.Soe. Japan, 13.163 . (1989). 